\title{
Fatal hypertensive intracerebral haematomas: a survey of the pathological anatomy of 393 cases
}

\author{
ELLA FREYTAG \\ From the Central Anatomic Laboratory of the Department of Mental Hygiene, and the \\ Chief Medical Examiner's Office of the State of Maryland, U.S.A.
}

The clinical and pathological aspects of hypertensive haematomas of the brain have repeatedly been the subject of statistical analysis (Russell, 1954; Dalsgaard-Nielsen, 1955; Anderson, 1956; Mutlu, Berry, and Alpers, 1963). These studies, however, were not concerned only with apoplectic haematomas, but also with haemorrhagic infarcts from embolism or thrombosis. Other analyses, while dealing solely with apoplectic haematomas, evaluated only supratentorial haematomas (Marks, 1960) or haematomas in one specific location, such as the cerebellum (Poór, 1967) or the pons (Epstein, 1951). Pathological surveys of a great number of cases representing all possible sites of hypertensive haematomas are rare. Because of the increasing interest in early diagnosis of the haematomas and their treatment by surgical removal (Davidoff, 1958; Lazorthes, 1959; Cuatico, Adib, and Gaston, 1965), more basic information is desirable.

Anatomically, these haematomas constitute a characteristic entity (National Institute of Neurological Diseases and Blindness, 1958). They usually dissect rather than destroy adjacent structures and may expand so rapidly that the life of the patient is acutely endangered. Most of the haematomas originate in certain areas of predilection where relatively large intracerebral arteries are present. These are the striate body branches of the middle cerebral arteries, of which the lateral and often largest one was called 'artère de l'hémorrhagie cérébrale' by Charcot; the thalamic branches of the posterior cerebral arteries, the largest being the arteria thalamoperforata; the branches of the basilar artery supplying the pons; those of the superior cerebellar arteries supplying the dentate nuclei and the deep white matter of the cerebellum; and some white matter branches of the cerebral arteries. Midbrain and medulla oblongata are practically never the site of origin of apoplectic haematomas.

\section{METHODS}

The present study was concerned solely with arterial intracerebral haematomas from hypertension, as evidenced by past clinical history and/or characteristic necropsy findings-for example, hypertrophy of the left heart. In all cases, the haematomas were large and represented the immediate cause of death or significantly contributed to it. Patients who recovered from a stroke and died later from unrelated causes were not included 0 In $80 \%$ of the cases necropsies were carried out at the Office of the Chief Medical Examiner, and in $20 \%$ ap general hospitals in Baltimore during a period of 17 yearsD (1951-67). All brains were examined by Dr. Richarc Lindenberg, Baltimore.

The cases were analysed as to age, sex, race, and survival time of the patients, and to the circumstances io which the vascular rupture took place. The pathologicat findings evaluated consisted of site of origin of the haematomas, rupture into the ventricles, penetration through the cortex into subarachnoid and subdural spaces, pressure effect on midbrain and pons, degree of arteriosclerosis of the cerebral arteries, and old lesions from previous vascular accidents.

\section{RESULTS}

SITES OF ORIGIN It was not usually difficult to determine the structure where the bleeding originated. If it involved several structures, the one in which it had its largest extent was considered to be the site of origin. The number of haematomas at each site for all patients, as well as for white and negro patients separately, are given in Table I. The greatest number $(42 \%)$ originated in the striate body area (striate body, external capsule, claustrum). Pons (16\%) and thalamus (15\%) were the seats of the next largest groups. Haematomas in the cerebellum comprised $12 \%$ of the total. Of the 38 haematomas in the cerebral white matter $(10 \%), 18$ were found in parietal and occipital areas, 16 in the temporal lobes, and four in the frontal lobes. The haematomas listed 
under 'various other locations' originated in the pallidum (two cases), the corpus callosum (two cases), and the wall of the lateral ventricles with bleeding solely into the ventricles (three cases). It should be mentioned that the cerebral and cerebellar haematomas occurred as often on the left as on the right side ( $51 \%$ on the left versus $49 \%$ on the right).

Thirteen cases $(3 \%)$ had multiple, moderately large, recent haematomas in various areas of the brain; 11 of them had two and the remaining two cases had three and five haematomas, respectively.

SURVIVAL TIMES The survival times of the patients are given in Table II. Thirty-five per cent were found dead or were dead on arrival at the hospital, and only $10 \%$ lived longer than three days. The longest survival time was 24 days. The length of survival depended, among other things, on the site of the haematoma. Immediate death or death within 24 hours occurred in $95 \%$ of the patients with pons haematomas as compared with $48 \%$ of those with haematomas in the cerebral white matter.

SEX, RACE, AND AGE DISTRIBUTION Table III shows the sex and race distribution among the patients and Table IV the grouping of all patients, and separately of white and negro patients, according to decades of life. The average age was 55.5 years, the youngest being 30 and the oldest 88 years old. While the total number of men $(62 \%)$ was much higher than that of women, the sex proportion varied within the age groups, as Fig. 1 shows. In the youngest age group (30-39 years), there was only a slight predominance of men. In the following decades, the number of men grew to almost twice of that of women, while after the age of about 70 years the female sex prevailed slightly.

The number of negroes among the patients was high $(48 \%)$ considering their percentage of Baltimore's population, which during the period of investigation rose from 25 to $42 \%$. The race proportion varied with the site of the haematoma. Table I shows that haematomas in the pons occurred much more often in negroes (39 cases) than in white patients (24 cases). Furthermore, negroes were on the average 12 years younger than white patients (49.2 versus 61.3 years). Figure 2 demonstrates that in the youngest age group the number of negroes was about six times higher than that of the white patients. This race difference, although decreasing, prevailed up to the age group of 50-59 years. From then on, the race proportion abruptly changed. In the age group of 60-69 years, the number of negroes was only about one-third of that of the white patients, and was even less in the older age groups.
The average age of the patients with haematomas in the same location was calculated for the most frequent sites (Table V). This revealed that pons haematomas occurred in both races at a younger age than haematomas in other locations.

VENTRICULAR, SUBARACHNOID, AND SUBDURAL BLEEDINGS The number of cases in which the

TABLE I

SITE OF INTRACEREBRAL HAEMATOMA

\begin{tabular}{lcccc} 
Site & \multicolumn{2}{l}{ All patients } & $\begin{array}{l}\text { White } \\
\text { (no.) }\end{array}$ & $\begin{array}{l}\text { Negro } \\
\text { (no.) }\end{array}$ \\
& $($ no. $)$ & $(\%)$ & & \\
\hline Striate body & 165 & 42 & 88 & 77 \\
Pons & 63 & 16 & 24 & 39 \\
Thalamus & 60 & 15 & 32 & 28 \\
Cerebellum & 47 & 12 & 22 & 25 \\
Cerebral white matter & 38 & 10 & 25 & 13 \\
Various other locations & 7 & 2 & 4 & 3 \\
Multiple & 13 & 3 & 10 & 3 \\
\hline & 393 & 100 & 205 & 188 \\
& & & $52 \%$ & $48 \%$
\end{tabular}

TABLE II

SURVIVAL TIME

\begin{tabular}{|c|c|c|c|c|c|c|c|c|}
\hline \multirow[b]{2}{*}{ Site } & \multicolumn{8}{|c|}{ Days } \\
\hline & $\begin{array}{l}D O A \\
\text { (no.) }\end{array}$ & $\begin{array}{l}1 \\
\text { (no.) }\end{array}$ & $\begin{array}{l}1-3 \\
\text { (no.) }\end{array}$ & $\begin{array}{l}4-7 \\
\text { (no.) }\end{array}$ & $\begin{array}{l}8-14 \\
\text { (no.) }\end{array}$ & $\begin{array}{l}15-21 \\
\text { (no.) }\end{array}$ & $\begin{array}{l}22-24 \\
\text { (no.) }\end{array}$ & $\begin{array}{l}\text { Sub- } \\
\text { total } \\
\text { (no.) }\end{array}$ \\
\hline Striate body & 52 & 68 & 30 & 5 & 6 & 4 & - & 165 \\
\hline Pons & 33 & 27 & 2 & - & - & - & 1 & 63 \\
\hline Thalamus & 17 & 28 & 6 & 2 & 4 & 2 & 1 & 60 \\
\hline Cerebellum & 23 & 16 & 5 & 2 & - & 1 & - & 47 \\
\hline $\begin{array}{l}\text { Cerebral white } \\
\text { matter } \\
\text { Various other }\end{array}$ & 9 & 9 & 13 & 3 & 4 & - & - & 38 \\
\hline locations & 2 & 3 & - & 1 & 1 & - & - & 7 \\
\hline Multiple & 3 & 5 & 1 & 3 & 1 & - & - & 13 \\
\hline $\begin{array}{c}\text { Total no. } \\
\%\end{array}$ & $\begin{array}{r}139 \\
35\end{array}$ & $\begin{array}{r}156 \\
40\end{array}$ & $\begin{array}{l}57 \\
14 \cdot 5\end{array}$ & $\begin{array}{r}16 \\
4\end{array}$ & $\begin{array}{r}16 \\
4\end{array}$ & $\begin{array}{l}7 \\
2\end{array}$ & $\begin{array}{c}2 \\
0.5\end{array}$ & $\begin{array}{l}393 \\
100\end{array}$ \\
\hline
\end{tabular}

TABLE III

\begin{tabular}{|c|c|c|c|c|c|c|}
\hline & $X$ AND & RACE & DISTRIB & UTIOI & & \\
\hline & $\begin{array}{l}\text { White } \\
\text { (no.) }\end{array}$ & $(\%)$ & $\begin{array}{l}\text { Negro } \\
\text { (no.) }\end{array}$ & $(\%)$ & $\begin{array}{l}\text { Total } \\
\text { (no.) }\end{array}$ & $(\%)$ \\
\hline $\begin{array}{l}\text { Male } \\
\text { Female }\end{array}$ & $\begin{array}{r}118 \\
87\end{array}$ & $\begin{array}{l}30 \\
22\end{array}$ & $\begin{array}{r}126 \\
62\end{array}$ & $\begin{array}{l}32 \\
16\end{array}$ & $\begin{array}{l}244 \\
149\end{array}$ & $\begin{array}{l}62 \\
38\end{array}$ \\
\hline Total & 205 & 52 & 188 & 48 & 393 & 100 \\
\hline
\end{tabular}

TABLE IV

AGE OF PATIENTS

\begin{tabular}{lrrrrrr} 
Years & \multicolumn{2}{c}{$\begin{array}{c}\text { All patients } \\
\text { (no.) }\end{array}$} & $\begin{array}{l}\text { Male } \\
\text { (white) }\end{array}$ & (negro) & $\begin{array}{l}\text { Female } \\
\text { (white) }\end{array}$ & (negro) \\
\hline $30-39$ & 44 & 11 & 2 & 22 & 4 & 16 \\
$40-49$ & 88 & 23 & 22 & 34 & 8 & 24 \\
$50-59$ & 117 & 30 & 31 & 47 & 23 & 16 \\
$60-69$ & 79 & 20 & 42 & 16 & 17 & 4 \\
$70-79$ & 48 & 12 & 15 & 6 & 26 & 1 \\
$80-88$ & 17 & 4 & 6 & 1 & 9 & 1 \\
\hline Total & 393 & 100 & 118 & 126 & 87 & 62
\end{tabular}


haematoma penetrated into the ventricles and into the subarachnoid and subdural spaces is given in Table VI. A total of $75 \%$ of the haematomas broke through the ventricular walls filling part of or the entire ventricle system. In many cases with supratentorial haematomas, not only the original haematoma penetrated into the lateral and third ventricles, but also a secondary pons haemorrhage broke into the fourth ventricle. In a few cases it was solely such secondary haemorrhage which entered

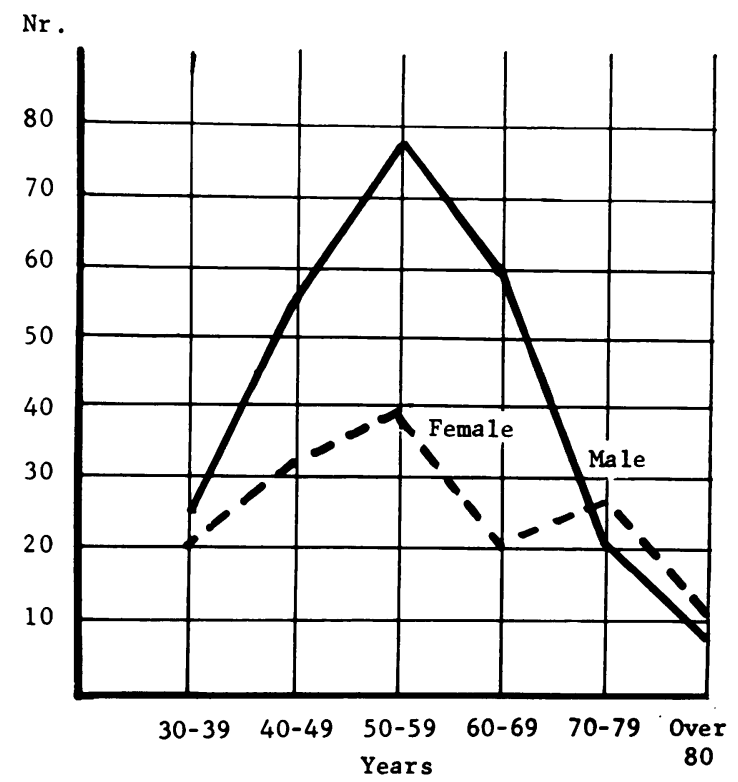

FIG. 1. Sex of patients in relation to age.

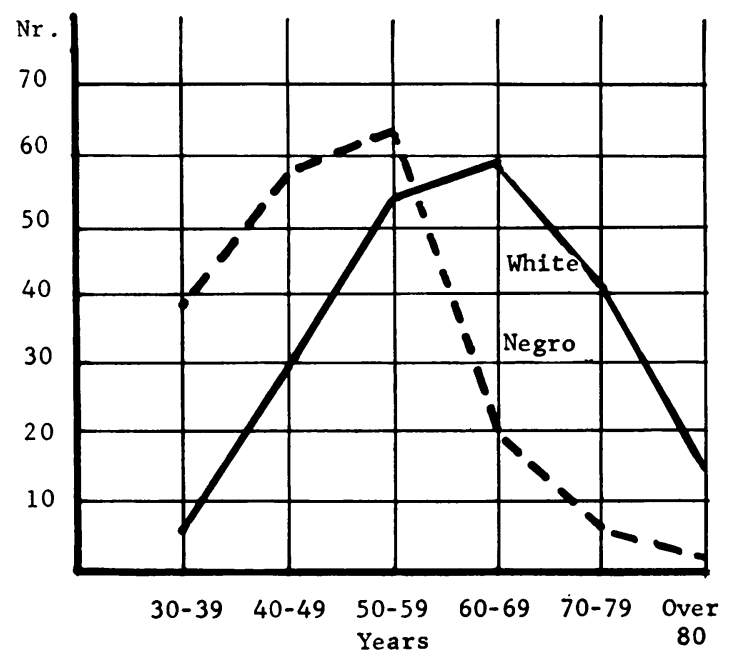

FIG. 2. Race of patients in relation to age.

the ventricular system, while the original haematoma remained confined to the brain tissues. The haematomas originating at sites close to the ventricleis wall penetrated into the ventricles more often than those in more remote areas. Thus, $97 \%$ of the thalamic, but only $40 \%$ of the cerebral white mattere haematomas broke through the ventricle wall.

In almost all cases with involvement of the ventricles, the haemorrhage extended through the. foramina of Luschka and Magendie into the sub- $\vec{F}$ arachnoid space. However, a subarachnoid haemor- $-\frac{\omega}{9}$ rhage from a rupture of the haematoma through the cortex was relatively rare $(15 \%)$, and never resulted $\frac{\overline{\bar{D}}}{\mathrm{D}}$ in a massive subarachnoid haematoma. The majority $\vec{\partial}$ of such subarachnoid haemorrhages originated from 2 haematomas in the cerebral white matter and in the cerebellum because of their closeness to the $\vec{\circ}$ subarachnoid space.

In 22 cases $(6 \%)$ the intracerebral haematoma $\overrightarrow{\vec{\omega}}$ penetrated through the arachnoid and extended $\stackrel{\circ}{\rightarrow}$ into the subdural space. This occurred most often with cerebellar haematomas.

SECONDARY LESIONS IN MIDBRAIN AND PONS Fiftyfour per cent of the patients with supratentorig $\vec{\sigma}$ haematomas lived long enough to develop secondañ oedema and haemorrhages in midbrain and pon\$. Aside from these secondary changes, the midbran 0 was directly involved by extension of thalamic $\mathbb{D}$ haematomas in 22 cases.

TABLE V

AVERAGE AGE OF PATIENTS RELATIVE TO SITE OF HAEMATOMAS

\begin{tabular}{lll} 
Site & $\begin{array}{l}\text { White } \\
(y r)\end{array}$ & $\begin{array}{l}\text { Negro } \\
(y r)\end{array}$ \\
\hline Striate body & $59 \cdot 7$ & $48 \cdot 2$ \\
Pons & 57.0 & $45 \cdot 8$ \\
Thalamus & $64 \cdot 7$ & $56 \cdot 2$ \\
Cerebellum & 64.9 & $49 \cdot 1$ \\
Cerebral white matter & $62 \cdot 4$ & 53.2
\end{tabular}

TABLE VI

PENETRATION OF HAEMATOMAS INTO VENTRICLES AND SUBARACHNOID AND SUBDURAL SPACES RELATIVE TO THEIR SITE

\begin{tabular}{|c|c|c|c|c|}
\hline Site & $\begin{array}{l}\text { Sub- } \\
\text { total } \\
\text { (no.) }\end{array}$ & $\begin{array}{l}\text { Ventricular } \\
\text { haemorrhage } \\
\text { (no.) }\end{array}$ & $\begin{array}{l}\text { Subarachnoid } \\
\text { haemorrhage } \\
\text { (no.) }\end{array}$ & $\begin{array}{l}\text { Subdural } \\
\text { haemorrhage } \\
\text { (no.) }\end{array}$ \\
\hline Striate body & 165 & 143 & 12 & 7 \\
\hline Pons & 63 & 41 & 4 & - \\
\hline Thalamus & 60 & 58 & $\overline{-}$ & 1 \\
\hline Cerebellum & 47 & 23 & 13 & 9 \\
\hline matter & 38 & 15 & 24 & 4 \\
\hline Various other & & & & \\
\hline locations & 7 & 6 & 2 & - \\
\hline Multiple & 13 & 8 & 4 & 1 \\
\hline $\begin{array}{c}\text { Total no. } \\
\%\end{array}$ & 393 & $\begin{array}{r}294 \\
75\end{array}$ & $\begin{array}{l}59 \\
15\end{array}$ & $\begin{array}{r}22 \\
6\end{array}$ \\
\hline
\end{tabular}


PRESENCE OF OLD VASCULAR LESIONS In $75 \%$ of the cases the recent haematoma was the first and only vascular lesion. The remainder showed evidence of a previous stroke. There were old haematomas, mostly in the form of slit-like defects with yellow or brown walls in $9 \%$, and old infarcts, usually small and multiple, in $16 \%$.

ARTERIOSCLEROSIS Since there is no absolute yardstick for measuring the amount of arteriosclerosis in the cerebral arteries, the degree of severity was estimated according to the number and size of plaques regardless of their effect on the lumen. If a few single plaques were present in one or the other artery, the arteriosclerosis was rated '1st degree'. If all arteries were most severely involved, it was called '4th degree'. Between these extremes, 2nd and 3rd degrees represented intermediate stages of severity. In seven cases the degree of arteriosclerosis was not stated in the necropsy note. Table VII shows that $33 \%$ of the remaining 386 cases had severe arteriosclerosis (3rd and 4th degree), and that in $42 \%$ it was of mild degree (1st and 2 nd degree), while $25 \%$ had no arteriosclerosis. In severe cases, the arteriosclerotic plaques were arranged in parallel rings resembling the rings of birch bark and extended into the convexity branches.

CIRCUMSTANCES UNDER WHICH RUPTURE TOOK PLACE In 57 cases the fatal rupture presumably occurred during sleep, since the patients were found lying in bed. However, the large majority of patients collapsed suddenly while awake and active. In many cases the events preceding the collapse were witnessed. In 10 cases the stroke occurred during a period of emotional excitement. Four of these were drivers who collapsed when they inspected their damaged cars after a minor accident, and in the other six cases the rupture took place during, or shortly after they were involved in fights. In none of the 10 cases had the accident resulted in traumatic lesions of the brain.

In regard to the effect of the seasons on the incidence of apoplexy, we were unable to find a significant difference. The number of cases per month varied

TABLE VII

SEVERITY OF ARTERIOSCLEROSIS

\begin{tabular}{lcc} 
Degree of severity & No. & $\%$ \\
\hline 1st & 96 & 25 \\
2nd & 64 & 17 \\
3rd & 84 & 22 \\
4th & 44 & 11 \\
\hline With arteriosclerosis & 288 & 75 \\
Without arteriosclerosis & 98 & 25 \\
\hline Total & 386 & 100
\end{tabular}

between 24 and 40 without showing a special trend.

\section{DISCUSSION}

Although necropsy has in its favour a wellestablished diagnosis, it suffers from the fact that the evaluated group of patients is usually not representative of the general population. By evaluating mostly Medical Examiner's cases, this inherent disadvantage was considerably minimized. In this way, the study included all persons who died unexpectedly from the intracerebral haematoma, because in Maryland every sudden unexplained death is subject to medicolegal necropsy by law. The selectivity was further reduced by limiting the cases to those in which the haematoma caused or essentially contributed to death, since it is common experience that with longer survival of the stroke, necropsies are less often performed.

In general, the data presented need no further elaboration, but it appears appropriate to point out a few findings which have some practical implications. Usually, a hypertensive haematoma is thought of as a potential cause of a stroke if the patient is between 40 and 60 years of age. If he is younger and the cerebrospinal fluid bloody, one is more inclined to attribute it to a ruptured angioma or aneurysm, to a haemorrhagic infarct from a nonarteriosclerotic vascular disease, or to venous thrombosis. If he is older than 60 years, one usually thinks first of an infarct from embolism or arteriosclerotic thrombosis of extra- or intracerebral arteries. While it is true that over $50 \%$ of the haematomas occurred between 40 and 60 years of age, no less than $11 \%$ of the patients suffered the haematoma in their 30 's, and $36 \%$ at an age of 60 years and older.

For differential diagnosis it is of interest that $54 \%$ of cases with ruptured aneurysms found in medicolegal necropsies (Freytag, 1966) were also between 40 and 60 years old. Also the circumstances under which the bleeding occurred and the survival times were very similar. In contrast, the apoplectic haematomas showed a difference in frequency and age distribution in regard to sex and race. Below the age of 40 and beyond that of 70 years, the number of male and female patients was almost equal, but at the age between 50 and 60 years twice as many men as women were struck. Concerning race, the number of negro patients was not only higher than their proportion within the population, but they suffered the apoplexy on the average 12 years earlier than the white patients. This was obviously related to the fact that arterial hypertension occurs more often and earlier in negroes than in white people (Merrill, 1962). 
In regard to the sites of the haematomas, it is worth noting that the pons and cerebellum are more often involved than it would appear from clinical experience. This is for the simple reason that about $50 \%$ of cases with bleedings in these structures do not come to the attention of physicians because the haematoma is rapidly fatal. In the present series only three out of 63 cases with pons apoplexy, and eight out of 47 cases with cerebellar haematomas lived longer than one day. It is of further interest that pons haematomas occurred at a younger age than haematomas in other locations and more often in negroes than in white patients.

For clinical purposes, it is important that patients with supratentorial haematomas had a much greater chance of immediate survival. About a quarter of those with haematomas in striate body and thalamus and half of those with haematomas in the cerebral white matter survived beyond one day.

As with all supratentorial space-occupying lesions, compression and distortion of the midbrain played an important role in the cause of death. Oedema and secondary haemorrhages in the midbrain were present in $54 \%$ of the cases. In other cases, death might be attributed to bleeding into the ventricles, especially if they were distended from pressure by the haemorrhage. The findings in an additional group of 83 cases with old apoplectic haematomas are of interest here. Since there was evidence of intraventricular haemorrhage in only $17 \%$ of these cases, they prove that, while this may be survived, the chance of survival is definitely greater if the ventricle wall remains intact. A few of the old haematomas were so large that one wonders why they were not quickly fatal. Apparently, the fate of the patient not only depends on site and size of the haematoma and on its rupture into the ventricles, but also on the speed of its development. It is well known in subdural haematomas that the more slowly the clot enlarges the greater the chance that respiratory and cardiac centres adjust to the emergency.

\section{SUMMARY}

A survey of 393 cases with hypertensive intracerebral haematomas revealed that the bleedings occurred most frequently in the striate body area $(42 \%)$. Pons $(16 \%)$ and thalamus $(15 \%)$ were the next most common sites, followed by cerebellum $(12 \%)$ and cerebral white matter $(10 \%)$. Seventy-five per cent of the haematomas ruptured into the ventricles, $15 \%$ extended through the cortex into the subarachnoid space and $6 \%$ through the arachnoid into the subdural space. Secondary pressure haemorrhages in midbrain and pons were present in $54 \%$ of the cases with supratentorial haematomas.

The length of survival depended on the structure involved by the haematoma. Almost all patients with pons haematomas died within one day in contrast to $48 \%$ of those with haematomas in the cerebral white matter. Sixty-two per cent of the patients were males and $48 \%$ were negroes. The average age of all patients was 55.5 years, the average age of negroes (49 years) being 12 years less than that of the white patients (61 years). Eleven per cent of all patients were younger than 40 years, and $36 \%$ older than 60 years. The sex and age distribution among the patients varied with their age. The number of men and women was almost equal at both ends of age curve, but at its peak (50-59 years) the number of men was twice that of women. Below the age of 60 years, the number of negroes was much higher than that of the white patients, thereafter, the proportion was reversed. Pons haematomas occurred at a younger age than haematomas in other locations and more often in negroes than in the white patients.

REFERENCES

Anderson, R. McD. (1956). Spontaneous intracranial haemorrhage a clinico-pathological report. Med. J. Aust., 1, 1043-1045.

Cuatico, W., Adib, S., and Gaston, P. (1965). Spontaneous intre cerebral haematomas. J. Neurosurg., 22, 569-575.

Dalsgaard-Nielsen, T. (1955). Survey of 1,000 cases of apoplexi cerebri. Acta psychiat. scand., 30, 169-185.

Davidoff, L. M. (1958). Intracerebral haemorrhage associated with hypertension and arteriosclerosis. J. Neurosurg., 15, 322-328.

Epstein, A. W. (1951). Primary massive pontine haemorrhage. A clinico-pathological study. J. Neuropath. exp. Neurol., 10, 426-448.

Freytag, E. (1966). Fatal rupture of intracranial aneurysms. Survey of 250 medico-legal cases. Arch. Path., 81, 418-424.

Lazorthes, G. (1959). Surgery of cerebral hac morrhage. Report on the results of 52 surgically treated cases. J. Neurosurg., 16, 355-364.

Marks, J. S. (1960). Apoplectic death due to intracerebral haemorrhage. An anatomic study. Neurology (Minneap.), 10, 278-280.

Merrill, John P. (1962). Hypertensive vascular disease, in Principles of Internal Medicine. Edited by T. R. Harrison, R. D. Adams, I. L. Bennett, W. H. Resnick, G. W. Thom, and M. M. Wintrobe. McGraw-Hill, New York.

Mutlu, N., Berry, R. G., and Alpers, B. J. (1963). Massive cerebral haemorrhage. Clinical and pathological correlations. Arch. Neurol., 8, 644-661.

National Institute of Neurological Diseases and Blindness. (1958). A classification and outline of cerebrovascular diseases. Neurology (Minneap.), 8, 395-434.

Poór, Gy. (1967). Úber hypertonische Kleinhirnblutungen. Acto med. Acad. Sci. hung., 24, 81-88.

Russell, D. S. (1954). The pathology of spontaneous intracranial haemorrhage. Proc. roy. Soc. Med., 47, 689-693. 